\title{
Determinants of Mammography in Women With Intellectual Disabilities
}

\author{
Joanne E. Wilkinson, MD, MSc, Emily Lauer, MPH, Karen M. Freund, MD, MPH, and \\ Amy K. Rosen, PhD
}

Background: Women with intellectual disabilities have the same rate of breast cancer as other women but are less likely to undergo screening mammography. Characteristics associated with mammography for women with intellectual disabilities in the United States are unknown.

Methods: This study was based on a secondary data analysis of the Massachusetts Department of Developmental Services database, comparing women who had a mammogram within 2 years with women who had not on variables related to the ecological model. Bivariate analyses, logistic regression, and assessment of interactions were performed.

Results: The study sample's $(n=2907)$ mean age was 54.7 years; $58 \%$ lived in 24 -hour residential settings, $52 \%$ received nursing health coordination, and more than $25 \%$ had clinical examination needs (eg, sedation). Residential setting, health coordination, and recent influenza vaccination were all associated with mammography. Having a guardian, higher level of activities of daily living needs, and examination needs (requiring sedation or limited wait time for examinations) were associated with lower rates. Interactions between health coordination and examination needs confirmed the potential of the nurse to ameliorate barriers to mammography.

Conclusion: Several system-level variables were significantly associated with mammography and, in some cases, seemed to ameliorate intrapersonal/behavioral barriers to mammography. Community agencies caring for intellectually disabled women have potential to impact mammography rates by using health coordination. (J Am Board Fam Med 2011;24:693-703.)

Keywords: Cancer Screening, Learning Disabilities

Adults with intellectual disabilities are increasingly likely to live in the community and be cared for by community primary care practices. ${ }^{1}$ Intellectually disabled adults are known to have health disparities, ${ }^{2}$ especially regarding preventive care and health screening. ${ }^{3,4}$ National efforts are underway $^{5,6}$ to identify the sources of these disparities and to improve screening/preventive services for

This article was externally peer reviewed.

Submitted 15 March 2011; revised 13 June 2011; accepted 22 June 2011.

From the Departments of Family Medicine (JEW) and General Internal Medicine (KMF), the Women's Health Interdisciplinary Research Center (KMF), School of Medicine; and the Department of Health Policy and Management, School of Public Health (AKR), Boston University, Boston, MA; the Center for Developmental Disabilities Evaluation and Research, University of Massachusetts Medical School, Waltham, MA (EL); and the Veterans Affairs Healthcare System Center for Organization, Leadership, and Management Research, Boston, MA (AKR).

Funding: This project was supported by award no. K07CA 134547 from the National Cancer Institute. adults with intellectual disabilities. One important disparity for women with intellectual disabilities is in breast cancer screening. ${ }^{7}$ Although the rate of breast cancer among women with intellectual disabilities $^{8,9}$ mirrors that of the general population, they seem to have higher mortality rates from

Prior presentation: Previously presented in part at the Northeast regional meeting of the Family Medicine Education Consortium, October 2008, Baltimore, MD, and October 2010, Hershey, PA; the North American Primary Care Group Annual Meeting, November 2009, Montreal, Canada, and November 2010, Seattle, WA; and the American Society of Preventive Oncology Annual Meeting, March 2010, Bethesda, MD.

Conflict of interest: none declared.

Corresponding author: Joanne E. Wilkinson, Department of Family Medicine, Dowling 5, Boston University School of Medicine, 840 Harrison Avenue, Boston, MA 02118 (E-mail: Joanne.Wilkinson@bmc.org).

See Related Article on Page 628. 
breast cancer (30.9 per 100,000 women with intellectual disabilities vs 24.2 per 100,000 women in the general population of women in Massachusetts since 2002). ${ }^{10,11}$ Though these estimates are based on small sample sizes, it is a provocative preliminary finding given that intellectually disabled women are also thought to have lower screening rates compared with the general population. The Center for Disease Control and Prevention's Behavioral Risk factor Surveillance System data report $75 \%$ of US women older than 40 having a mammogram, and in Massachusetts that number is $85 \% .^{12}$ Rates of mammography among women with intellectual disabilities are significantly lower internationally ${ }^{13,14}$ (12\% to $\left.30 \%\right)$ and are unknown in the US. Researchers are investigating individual-, caregiver-, and system-level issues linked to this disparity. ${ }^{15}$ Because most people with intellectual disabilities live in the community and are patients of neighborhood primary care practices, it is important to consider their unique vulnerabilities and barriers to screening when striving to deliver care in the patient-centered medical home.

An intellectual disability is defined as an intelligence quotient at least 2 standard deviations below the mean accompanied by significant difficulties in at least one area of adaptive functioning: conceptual (language); social (understanding of and ability to follow rules, gullibility, interpersonal relationships); and practical (activities of daily living, taking medications, handling money). ${ }^{16}$ These difficulties must exist before age 18. Because the diagnosis of intellectual disabilities encompasses multiple areas of function, the ecological mode ${ }^{17}$ is most appropriate when considering theories of health behavior applicable to breast cancer screening (Table 1), particularly the intra- and interpersonal and "institutional" (referred to herein as "system-level") domains. This model is particularly well-suited to women with intellectual disabilities because they may make health care decisions with some amount of support-from family, staff, or a guardian/agency charged with their care. Therefore, the multiple environmental domains of this model provide a broader perspective for intellectually disabled women. Interactions between domains also may be relevant for understanding associations with screening mammography. The aim of this study was to determine characteristics associated with mammography, both variables and interactions between variables, related to domains of the ecological model. A secondary aim was to make preliminary recommendations based on these findings for interventions to improve screening and prevention of breast cancer in women with intellectual disabilities in the setting of the patient-centered medical home.

\section{Methods \\ Database}

The Massachusetts Department of Developmental Services (DDS) began collecting and tracking health information on clients with intellectual dis-

Table 1. Proposed Domains of the Ecologic Model Affecting Breast Cancer Screening for Women with Intellectual Disabilities

\begin{tabular}{|c|c|c|c|}
\hline Concept & Concept Description & $\begin{array}{c}\text { Example of Effect on Breast Cancer } \\
\text { Screening }\end{array}$ & Related Variables of Interest \\
\hline Intrapersonal & $\begin{array}{l}\text { Individual factors or ideas } \\
\text { influencing behavior }\end{array}$ & $\begin{array}{l}\text { Extremely anxious about mammogram } \\
\text { so does not have one }\end{array}$ & $\begin{array}{l}\text { Psychiatric diagnoses } \\
\text { Requires sedation or other } \\
\text { accommodations for clinical visits } \\
\text { Down syndrome } \\
\text { Functional status }\end{array}$ \\
\hline Interpersonal & $\begin{array}{l}\text { Social supports, family, peer } \\
\text { groups influencing } \\
\text { behavior }\end{array}$ & $\begin{array}{l}\text { Supportive guardian encourages } \\
\text { patient to go and accompanies her }\end{array}$ & $\begin{array}{l}\text { Communication status } \\
\text { Whether guardian is assigned } \\
\text { Whether subject is receiving other } \\
\text { screening/preventive services }\end{array}$ \\
\hline Institutional & $\begin{array}{l}\text { Rules and policies that may } \\
\text { promote or prevent } \\
\text { behavior }\end{array}$ & $\begin{array}{l}\text { Residential program provides care } \\
\text { coordination by a nurse and } \\
\text { encourages cancer screenings }\end{array}$ & $\begin{array}{l}\text { Residential setting } \\
\text { Day/work program } \\
\text { Care coordination by registered nurse }\end{array}$ \\
\hline Community & $\begin{array}{l}\text { Social groups/organizations } \\
\text { in the community that } \\
\text { can be formal or informal }\end{array}$ & $\begin{array}{l}\text { Advocacy organizations for adults with } \\
\text { disabilities publishes information } \\
\text { encouraging mammography }\end{array}$ & None in this database \\
\hline Public policy & $\begin{array}{l}\text { Local policies and laws to } \\
\text { support healthy behaviors }\end{array}$ & $\begin{array}{l}\text { Publications raise awareness of } \\
\text { physicians about preventive services } \\
\text { for adults with disabilities }\end{array}$ & None in this database \\
\hline
\end{tabular}


abilities within the last 10 years. We obtained data for this study from these administrative "health record" entries of this electronic client management database, which was tailored for the needs of adults with intellectual disabilities and included information about functional status and special needs related to medical care. It is important to note that these records are not the same as electronic medical records used by health care providers. The database is used to track health outcomes for clients of DDS, not to provide medical care. It was determined through prior analyses ${ }^{18}$ that the database does not have uniform representation of all clients. The database is most generalizable to women with intellectual disabilities living in residential settings with 24-hour support ( $>90 \%$ of clients in this group were represented in the database). The mammography data in the DDS database were validated using matched records from a large electronic medical record database in Boston, ${ }^{18}$ and a high correlation in data element reliability was found between the databases.

The state requires annual updates of this record by the service provider and recommends updating whenever the individual's information changes significantly. Information about each subject's service enrollment, such as state-funded residential programs, was taken directly from enrollment tables, which are updated frequently, when enrollment determines payment to the service provider.

Subjects were included in the analyses if they were women 42 to 74 years old on January 1, 2007 (to ensure that all were eligible for mammography for the entire time period), eligible for state services for at least 1 month between October 2007 and April 2009, and had complete records. To eliminate exposure time bias, subjects were included only if they had documentation for the entire time period. Reporting bias was minimized by collecting data on mammograms completed between January 1, 2007, and December 31, 2008, but entered into the database between December 31, 2008, and April 30, 2009. Women with a history of breast cancer were excluded. Also excluded were approximately 200 women who were 75 years of age or older because data currently reflect no mortality benefit from screening women in this age group. ${ }^{19}$

\section{Variables}

Dependent

Appropriate breast cancer screening was defined as having received a mammogram between January 1 ,
2007, and December 31, 2008 (yes or no). During this time period, most guidelines recommended mammography every 1 to 2 years starting at age 40. ${ }^{19}$ (We did perform a sensitivity analysis looking only at subjects aged 50 years and older because of the revised recommendations in 2009). "Unknown" mammograms were classified as not completed because the scheduling/logistic issues involved (transporting the person to a separate test) make it likely that either the subject or her caregiver would remember the mammogram if it had occurred.

\section{Independent}

Information about independent variables was captured for each subject at baseline to 6 months before the period in which mammography screening was examined. Several variables were examined related to the intrapersonal domain of the ecological model. Age was analyzed categorically (40-49 years, $50-59$ years, $60-69$ years, and $\geq 70$ years). A summary score of 0 to 4 was created for functional status based on assistance needs with four activities of daily living (ADLs): toileting, eating, personal hygiene, and ambulation. A separate variable was included for psychiatric diagnoses (one or more vs none, two or more vs none, three or more vs none; sensitivity analyses compared this classification with a classification by type of psychiatric diagnosis) and another for Down syndrome (because of possible lower rates of breast cancer). ${ }^{20,21}$ Variables related to clinical visits were examined: need for special positioning, sedation, or limited waiting times or a tendency to be "uncooperative" during medical visits. Variables from the interpersonal domain included communication (able vs unable using any modality) and the assignment of a guardian.

Variables were examined related to the receipt of other preventive services (Papanicolaou smear, influenza vaccination after 2007, and colonoscopy/ sigmoidoscopy and bone densitometry for women older than 50 years) as belonging to the "institutional," or system-level, domain. Receipt of the influenza vaccine was selected as a recent care marker in multivariate analyses because it is an easily administered annual preventive measure generally recommended for this population, ${ }^{22}$ and its receipt likely signifies that the support staff and agencies involved with the client are pursuing preventive services for them.

Other variables related to the system-level domain were also examined, including several catego- 
ries of residential setting: state-funded 24-hour support (usually provided in group home settings) and less than 24-hour support, which is a combination of shared living, subjects living independently or with family, or subjects receiving limited support at home. Health coordination by a registered nurse $(\mathrm{RN})$ was also examined because many subjects receive health coordination by nurses familiar with the health needs of this population. Nurses review clients' records and make recommendations regarding medications, side effects, chronic conditions, and testing/evaluation. The $\mathrm{RN}$ is involved in planning for physical examinations and/or accompanies the patient to the visit, so they may influence the receipt of preventive services. Health insurance was not examined; more than $95 \%$ of the participants had Medicaid benefits.

\section{Statistical Analyses}

Bivariate analyses identified variables associated with mammography. To assess for multicollinearity, a Pearson correlation matrix was constructed between all variables considered for inclusion in multivariate regression, and tolerance/variance inflation factors were reviewed. A multivariate logistic regression model was built through stepwise reduction; the dependent variable was "recent mammography." The multivariate model was first built with univariate-level variables, using a significance criterion of 0.05 for the Wald $\chi^{2}$ as the elimination threshold. This step was repeated using Akaike Information Criterion statistics ${ }^{23}$ and yielded similar results. Interactions were tested across domains of the ecological model based on consultation of the literature and health care experts in intellectual disabilities. Two-way interactions (age as a categorical variable, care coordination by a nurse, and 24-hour supported residential setting) were tested for all variables. Finally, a three-way interaction between guardian status, nursing coordination, and being "uncooperative" or requiring limited waiting times during examinations was tested to examine how the presence of a guardian affects the interaction between these two predictors. SAS software (version 9.2, SAS Inc, Cary, NC) was used for all analyses. Several sensitivity analyses were also performed (see Table 2). For example, we examined the subset of women who did not receive the influenza vaccine; within this subset, we compared those who did and did not receive breast cancer screening.

\section{Multivariate Model's Predictive Ability}

To assess the model's sensitivity and specificity, the estimated model was applied to the dataset, and the

Table 2. Methods and Results of Sensitivity Analyses Performed

\begin{tabular}{|c|c|c|}
\hline Variable of Interest & Methods Used to Perform Sensitivity Analyses & Results \\
\hline ADLs & $\begin{array}{l}\text { Each individual ADL score was compared to } \\
\text { the summary score. Two different grouped } \\
\text { levels of summary score were tested. }\end{array}$ & No significant improve in the model \\
\hline Psychiatric diagnosis & $\begin{array}{l}\text { Types of psychiatric diagnoses (eg, anxiety, } \\
\text { psychosis) were compared to the number of } \\
\text { diagnoses recorded (one, two, three or more } \\
\text { vs none). }\end{array}$ & No significant improve in the model \\
\hline Age & $\begin{array}{l}\text { Categorical groupings in Table } 1 \text { were } \\
\text { compared with continuous variable versus } \\
\text { categorical groupings with the last category } \\
\text { of } \geq 60 \text { years. }\end{array}$ & No significant improve in the model \\
\hline 24-Hour residential setting & $\begin{array}{l}\text { Entire analysis was re-run using only clients } \\
\text { from 24-hour residential settings because } \\
\text { their representation in the database was } \\
\text { relatively complete. }\end{array}$ & $\begin{array}{l}\text { All variables remained in the model except } \\
\text { guardian and summary ADL score. } \\
\text { Effect sizes were similar but slightly higher for all } \\
\text { remaining variables in the model. } \\
\mathrm{C} \text { statistic }=0.723\end{array}$ \\
\hline Recent influenza vaccination & $\begin{array}{l}\text { Characteristics of influenza vaccine were } \\
\text { negative; women who did not receive a } \\
\text { mammogram were analyzed and compared } \\
\text { with women who did receive a mammogram } \\
\text { and had influenza. }\end{array}$ & $\begin{array}{l}\text { Less able to communicate ( } 64 \% \text { vs } 79 \%) \\
\text { More likely to have a guardian }(58 \% \text { vs } 46 \%) \\
\text { Less likely to have one or psychiatric diagnosis } \\
\quad(54 \% \text { vs } 62 \%) \\
\text { More likely to have high ADL need ( } 31 \% \text { vs } 19 \%) \\
\text { More likely to require sedation }(22 \% \text { vs } 15 \%)\end{array}$ \\
\hline
\end{tabular}

ADL, activity of daily living. 
model's predicted mammography outcome for each subject was compared with their observed outcome.

\section{Results}

There were 2907 subjects included in the analysis. One hundred ninety-five records $(6 \%)$ were excluded because of missing values. The average age of the cohort was 54.7 years (median, 53.6 years; $\mathrm{SD}, 8.2$ years; range, $42.0-74.9$ years).

The overall mammography rate was $53 \%$. Table 3 shows the bivariate analyses of mammography receipt. All the variables except age show statistically significant $(P<.05)$ associations with mammography. In the intrapersonal domain, all the categories reflecting higher need for support (needing special positioning, uncooperative during examinations, higher ADL need) were associated with lower odds of mammography (odds ratios [ORs] ranging from 0.69 to 0.84 ) except psychiatric diagnoses: subjects with a higher number of diagnoses had higher odds of receiving a mammogram. Among system-level variables, residential setting (unadjusted OR, 1.32; 95\% CI, 1.14-1.53) and health coordination by an RN (OR, 1.40; 95\% CI, 1.21-1.63) are most strongly associated with mammography. All the preventive care variables were strongly associated with mammography, with recent influenza vaccination being the strongest (OR, 4.38, 95\% CI 3.74 to 5.12).

Table 4 shows results from the multivariate regression model. After adjusting for other variables in the model, the system-level factor most positively associated with mammography was receipt of influenza vaccination in the same time period (adjusted OR, 4.67; 95\% CI, 3.84-5.66). Intrapersonal factors such as high ADL need (adjusted OR, 0.68; 95\% CI, 0.55-0.84); requiring special positioning for examination (adjusted OR, 0.65; 95\% CI, 0.440.95); and having Down Syndrome (adjusted OR, $0.63 ; 95 \%$ CI, 0.48-0.82) were associated with lack of mammography. Family history of breast cancer was positively associated with mammography (adjusted OR, 1.91; 95\% CI, 1.35-2.70). Finally, two interpersonal variables showed significant associations: ability to communicate (adjusted OR, 1.44; 95\% CI, 1.14-1.81) was positively associated with mammography, and assignment of a guardian (adjusted OR, 0.77; 95\% CI, 0.61-0.95) was negatively associated with mammography. The $\mathrm{C}$ statistic for the final model was 0.728 .
Two interactions illustrate the mitigating effect of system-level factors on barriers to mammography presented by intrapersonal factors. A significant interaction was noted between the subjects labeled "uncooperative" or limited waiting period and having health coordination by RN. Subjects who were labeled "uncooperative" or required a limited wait time for examinations were less likely to obtain mammography (adjusted OR, 0.79; 95\% CI, 0.71-0.89) than those who were cooperative and did not require a limited wait. However, when "uncooperative" subjects also had health coordination, they did not exhibit significantly different odds of mammography (adjusted OR, 0.92; 95\% CI, 0.81-1.05) compared with subjects who were considered cooperative. In addition, a significant interaction was noted between a subject's ADL score and the presence of 24-hour residential supports. Subjects with high daily assistance needs (support needs in three or more domains across four total) were less likely to receive mammograms if they received less than 24-hour residential supports (adjusted OR, 0.77; 95\% CI, 0.68-0.87). In comparison, subjects with similar support needs who received 24-hour residential supports had odds of receiving a mammogram (adjusted OR, 0.88; 95\% CI, 0.78-1.01) statistically similar to subjects in this setting with lower support needs. Results of the sensitivity analyses are summarized in Table 2.

We also looked at the effect of removing subjects in the 40- to 50-year-old age range from the analyses because the US Preventive Services Task Force guidelines were reissued during the course of this research project and emphasized routine screening mammography in women 50 and older. We found that when the analyses were repeated with subjects only 50 years of age and older, the overall findings were quite similar (eg, the effects of residential setting, health coordination by $\mathrm{RN}$, requiring sedation for visits, ADL status) but that a few variables were not included in the final model: communication status, having a guardian, and needing special positioning for examinations (the last variable did not reach statistical significance because of the smaller sample size when women 40 to 50 years old were excluded).

\section{Predictive Ability}

The model demonstrated a sensitivity of $75.3 \%$ and a specificity of $59.3 \%$. The positive predictive value 
Table 3. Variables Associated With Screening Mammography in Women With Intellectual Disabilities-Bivariate Analysis

\begin{tabular}{|c|c|c|c|}
\hline Variables & $\begin{array}{c}\text { Patients } \\
(\mathrm{N}=2907)\end{array}$ & $\begin{array}{c}\text { Patients With } \\
\text { Mammogram* (\%) }\end{array}$ & $\begin{array}{l}\text { Unadjusted Odds } \\
\text { Ratio }(95 \% \mathrm{CI})\end{array}$ \\
\hline \multicolumn{4}{|l|}{ Intrapersonal } \\
\hline \multicolumn{4}{|l|}{ Age (years) } \\
\hline $40-49$ & 1022 & 51 & $0.89(0.75-1.05)$ \\
\hline $50-59$ & 1119 & 54 & Reference \\
\hline $60-69$ & 617 & 55 & $1.04(0.85-1.27)$ \\
\hline $70-74$ & 149 & 46 & $0.73(0.52-1.03)$ \\
\hline \multicolumn{4}{|l|}{ Psychiatric diagnosis } \\
\hline$\geq 1$ & 1785 & 55 & $1.44(1.24-1.67)$ \\
\hline$\geq 2$ & 786 & 57 & $1.30(1.10-1.53)$ \\
\hline$\geq 3$ & 258 & 61 & $1.45(1.12-1.89)$ \\
\hline None & & & Reference \\
\hline \multicolumn{4}{|l|}{ ADLs (summary score) } \\
\hline 0 & 816 & 57 & \\
\hline 1 & 485 & 54 & Reference \\
\hline 2 & 377 & 53 & \\
\hline 3 & 408 & 46 & $0.78(0.66-0.91)$ \\
\hline 4 & 585 & 48 & \\
\hline \multicolumn{4}{|c|}{ Requires sedation for clinical visits } \\
\hline Yes & 652 & 50 & $0.81(0.68-0.96)$ \\
\hline No & 2070 & 56 & Reference \\
\hline \multicolumn{4}{|c|}{ Requires special positioning for exams } \\
\hline Yes & 159 & 48 & $0.73(0.53-1.00)$ \\
\hline No & 2496 & 56 & Reference \\
\hline \multicolumn{4}{|c|}{ Uncooperative or requires limited waiting period } \\
\hline Yes & 725 & 50 & $0.77(0.65-0.92)$ \\
\hline No & 1921 & 57 & Reference \\
\hline \multicolumn{4}{|l|}{ Down syndrome } \\
\hline Yes & 383 & 43 & $0.64(0.53-0.80)$ \\
\hline No & 2524 & 54 & Reference \\
\hline \multicolumn{4}{|c|}{ Family history of breast cancer } \\
\hline Yes & 212 & 67 & $1.85(1.37-2.48)$ \\
\hline No & 2695 & 52 & Reference \\
\hline \multicolumn{4}{|l|}{ Interpersonal } \\
\hline \multicolumn{4}{|l|}{ Guardian assigned } \\
\hline Yes & 1811 & 50 & $0.76(0.65-0.89)$ \\
\hline No & 1096 & 57 & Reference \\
\hline \multicolumn{4}{|l|}{ Able to communicate } \\
\hline Yes & 1780 & 57 & $1.54(1.32-1.78)$ \\
\hline No & 1113 & 47 & Reference \\
\hline \multicolumn{4}{|l|}{ System level } \\
\hline \multicolumn{4}{|l|}{ Residential setting } \\
\hline 24-hour support & 1700 & 56 & $1.32(1.14-1.53)$ \\
\hline Not 24-hour support & 1207 & 49 & Reference \\
\hline \multicolumn{4}{|c|}{ Health coordination by $\mathrm{RN}$} \\
\hline Yes & 1525 & 57 & $1.40(1.21-1.63)$ \\
\hline No & 1382 & 48 & Reference \\
\hline \multicolumn{4}{|c|}{ Colon cancer screening (age $\geq 50$ years) } \\
\hline Yes & 761 & 68 & $2.18(1.73-2.73)$ \\
\hline No & 539 & 49 & Reference \\
\hline
\end{tabular}


Table 3. Continued

\begin{tabular}{|c|c|c|c|}
\hline Variables & $\begin{array}{c}\text { Patients } \\
(\mathrm{N}=2907)\end{array}$ & $\begin{array}{c}\text { Patients With } \\
\text { Mammogram* (\%) }\end{array}$ & $\begin{array}{l}\text { Unadjusted Odds } \\
\text { Ratio }(95 \% \text { CI })\end{array}$ \\
\hline \multicolumn{4}{|c|}{ Bone density screening (age $\geq 50$ years) } \\
\hline Yes & 943 & 68 & $2.46(1.90-3.17)$ \\
\hline No & 334 & 46 & Reference \\
\hline \multicolumn{4}{|c|}{ Ever had Pap or GYN exam } \\
\hline Yes & 1935 & 64 & $3.81(3.24-4.49)$ \\
\hline No & 972 & 31 & Reference \\
\hline \multicolumn{4}{|c|}{ Flu vaccine given 2007 or after } \\
\hline Yes & 1690 & 68 & $4.38(3.74-5.12)$ \\
\hline No & 1217 & 32 & Reference \\
\hline
\end{tabular}

*Mammogram occurred between January 1, 2007, and December, 312008.

ADL, activity of daily living; RN, registered nurse; GYN, gynecologic; Pap, Papanicolaou smear.

was $70.2 \%$ and the negative predictive value was $65.4 \%$.

\section{Discussion}

There are few data about screening mammography in the United States among women with intellectual disabilities. These data indicate an overall rate of screening within the past 2 years of $53 \%$. This is higher than other non-US populations of women with intellectual disabilities but much lower than the rate of $84.9 \%$ found in the general population in Massachusetts. ${ }^{12}$ These data show several individual and system-level variables positively associated with mammography in intellectually disabled women: living in 24-hour supported residential settings, having health coordination by a nurse, having a family history of breast cancer, receiving the influenza vaccine (a likely marker for preventive care), and communication ability. Though not all these variables are modifiable, several have been associated with preventive care in other studies. Some variables were negatively associated with mammography: having a guardian, Down syndrome, or higher levels of ADL needs. In the sensitivity analysis examining only subjects living in 24-hour residential settings, ADL needs and having a guardian disappeared from the final model.

The association of health coordination by a nurse with mammography (and particularly the interaction between health coordination and special needs relative to the examination) underscores the potential of an $\mathrm{RN}$ already involved with the subject to positively advocate for them to receive preventive services. Though few rigorous studies have analyzed the impact of health coordination on health care for people with intellectual disabilities, ${ }^{24}$ the relationship has been noted indirectly. For example, researchers note that nurses play an important role in facilitating access to breast cancer screening for women with intellectual disabili$\operatorname{ties}^{25-27}$ in terms of both helping their clients overcome barriers to screening and the effect of their own knowledge about screening on their clients' screening patterns. During health coordination activities, it is likely that the RN prompts the health care provider to consider a mammogram and then problem-solves the logistic aspects of getting the test for the client (ie, calling the mammography center to reserve extra time or ensuring that women who require sedation are adequately medicated and the staff are prepared for the experience). For older women in the general population, researchers have noted that practice-level factors ${ }^{28}$ and relationship-centered aspects of the medical home ${ }^{29}$ affect preventive screening, again pointing to the potential for a health care professional to advocate for preventive services.

Though the population of women living outside settings with 24-hour support was not as well represented in this study, the above findings likely have significance for this group as well. We suspect that women with intellectual disabilities who live more independently in the community or with family are less able to consistently access preventive care. They may also receive advice and assistance from family members who are not as well-informed about prevention as the $\mathrm{RN}$ providing health care coordination would be. For example, having a guardian was associated with a lower likelihood of 


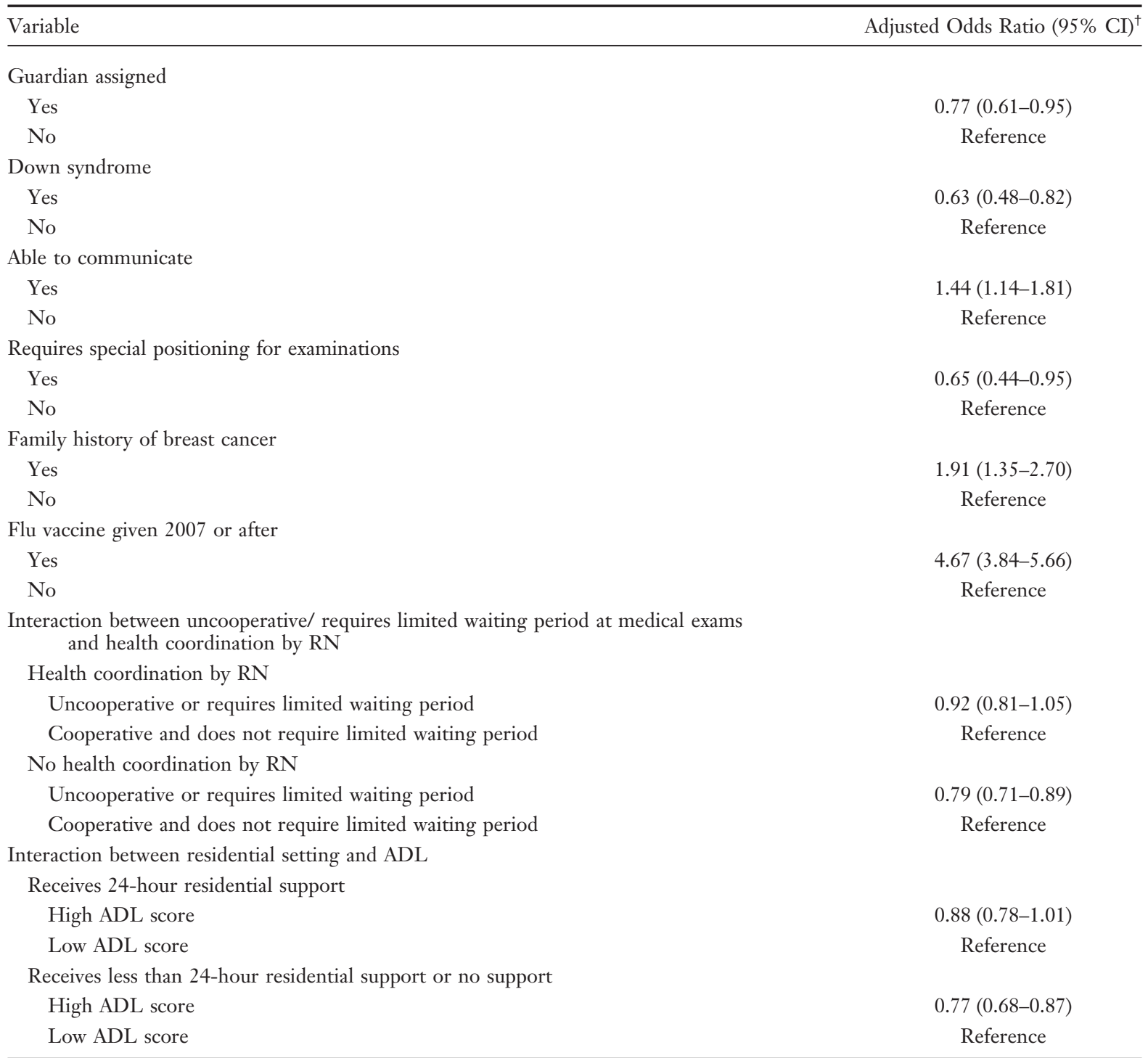

${ }^{*} \mathrm{C}$ statistic $=0.728$.

${ }^{\dagger}$ Final model.

ADL, activity of daily living; RN, registered nurse.

mammography, except in the population of women living in settings with 24-hour support.

For women living outside these residential settings, the issue of how to approximate health care coordination and improve access is not easily resolved. One potential solution would be to shift that responsibility to the health care provider, requesting that all primary care practices review the prevention and screening practices for vulnerable patients (potentially extending beyond women with intellectual disabilities), facilitating their involvement in screening and prevention. The patientcentered medical home movement may be an excel- lent initiative to develop practice-based procedures and/or pilot interventions around this issue. However, these potential solutions do not address the issue of women with intellectual disabilities in the community who do not receive consistent primary care.

An interesting and somewhat counterintuitive finding was the association of higher numbers of psychiatric diagnoses with mammography. Although this finding is preliminary (based on secondary data analyses), one potential explanation is that women with psychiatric diagnoses in their record probably receive care and medication for these 
diagnoses, potentially affecting their ability to tolerate the anxiety of mammography.

In addition, subjects with high ADL support needs (requiring assistance in at least three domains out of four) who did not receive 24-hour residential supports were less likely to receive mammography. It is unknown whether this is reflective of a more medically complex, fragile group who may not represent good candidates for screening and preventive care versus a group overwhelmed by the logistic difficulties of getting some of these patients to the examination. However, because this barrier seems to be ameliorated by the involvement of 24-hour residential supports, it is likely at least some of these subjects represent people who are good candidates for screening but experience logistic challenges. Researchers have noted health disparities among people with disabilities who have relatively more functional impairments ${ }^{30}$ and an increased likelihood of preventive care for people with intellectual disabilities who live in 24-hour residential settings. ${ }^{31}$ Future research should determine whether the high ADL support needs generally represent a person who may not be considered eligible for screening versus someone who is eligible but is not receiving mammograms.

It was also intriguing to note low rates of mammography among women with Down syndrome. There are scant US data on this topic, but European researchers have suggested that the breast cancer risk is so low for women with Down syndrome that they are actually at higher risk of radiation injury from mammography ${ }^{20}$ and should be counseled not to have routine mammography. It is unclear whether the low rates among women with Down syndrome in our population reflect application of this recommendation by US physicians. It has not been shown, however, that there is a significant risk of radiation injury from mammography for women without Down syndrome. ${ }^{32}$

This study had several limitations. Because mammography is not a rare event, the ORs presented here are higher than a comparable rate ratio would be; ORs were used to be consistent with other, similar studies. The database, though highly representative of women with intellectual disabilities who live in supported settings, has lower representation of women who live with families or in the community without state supports. Therefore, generalizing to the entire population of intellectually disabled women is not possible. Second, this database was designed for other purposes and lacked certain variables that are usually considered, ie, race, ethnicity, and level of education. Third, some records may have underreporting of certain disabilities or medical conditions. However, these misclassifications are not suspected to be biased with regard to mammography screening. Fourth, the database lacked information about obesity, which is known to be common in people with intellectual disabilities ${ }^{3-35}$ and to be associated with lower rates of screening for some cancers. ${ }^{36}$ Fifth, because the study was conducted in Massachusetts, a state that has universal health insurance, we were unable to assess the impact of lack of insurance coverage on the likelihood of mammography. Despite these limitations, this database is large, only includes intellectually disabled women, and yielded results that confirmed the model's validity.

Several Federal initiatives ${ }^{5,6}$ have encouraged providers and health systems to improve primary and preventive care for adults with intellectual disabilities. These data indicate potential areas for intervention; at the system level, health coordination could be broadened or made available to more clients, and guardians could be targeted for more education about screening and health recommendations for people with intellectual disabilities. At the provider level, women with intellectual disabilities who do not live in supported settings could be particularly vulnerable and should be educated and supported in pursuing breast cancer screening. ${ }^{37}$ Primary care physicians also should be aware of the extent to which residential setting can determine prevention and screening opportunities for people with intellectual disabilities. These findings should be helpful in increasing awareness of characteristics associated with lower rates of screening and prevention for members of a vulnerable, underserved population present in many community primary care practices.

The authors thank Pamela Ohman Strickland, MS, $\mathrm{PhD}$, at the University of Medicine and Dentistry of New Jersey School of Public Health, for her review and comments on the statistical methods of this article. We also thank the Massachusetts Department of Developmental Services for providing access to data.

\section{References}

1. Chew KL, Iacono T, Tracy J. Overcoming communication barriers - working with patients with intellectual disabilities. Austr Fam Phys 2009;38(1-2):10-4. 
2. Anderson D, Lakin K, Bruininks R, Hill B. A national study of residential and support services for elderly persons with mental retardation. Minneapolis, MN: Center for Residential and Community Services, University of Minnesota; 1987.

3. Iacono T, Sutherland G. Health screening and developmental disabilities. J Pol Prac Intell Disabil 2006;3(3):155-63.

4. Wilkinson JE, Cerreto MC, Culpepper LC. Primary care screening tests for adults with intellectual disabilities. J Am Board Fam Med 2007;20(7):399-407.

5. US Department of Health and Human Services. Healthy People 2010. Available at: www.healthypeople. gov [homepage]. Accessed 25 September 2011.

6. US Department of Health and Human Services. Closing the Gap: A National Blueprint to Improve the Health of Persons with Mental Retardation. Report of the Surgeon General's Conference on Health Disparities and Mental Retardation. Available at: http:// www.surgeongeneral.gov/topics/mentalretardation/ retardation.pdf. Accessed 27 February 2007.

7. Wilkinson JE, Cerreto MC. Primary care for women with intellectual disabilities. J Am Board Fam Med 2008;21:215-22.

8. Sullivan SG, Hussain R, Threlfall T, Bittles AH. The incidence of cancer in people with intellectual disabilities. Cancer Cause Control 2004;15:1021-5.

9. Patja K, Eero P, Iivanainen M. Cancer incidence among people with intellectual disability. J Intell Disabil Res 2001;45(Pt 4):300-7.

10. Center for Developmental Disabilities Evaluation and Research, Commonwealth of Massachusetts Executive Office of Health and Human Services, Department of Mental Retardation. 2007 mortality report. Available at: http://www.mass.gov/Eohhs2/docs/ dmr/mortalityreport2007.pdf. Accessed 21 September 2010.

11. Cancer Incidence and Mortality in Massachusetts, http://www.mass.gov/Eeohhs2/docs/dph/cancer/ registry_statewide_03_07_report.pdf. Accessed 7 October 2011.

12. Centers for Disease Control and Prevention. Behavioral risk factor surveillance system. Prevalence and trends data. Massachusetts-2008 women's health: women aged $40+$ who have had a mammogram within the past two years. Available at http://apps. nccd.cdc.gov/brfss/display.asp? $\mathrm{cat}=\mathrm{WH} \& \mathrm{yr}=2008 \&$ qkey $=4421 \&$ state $=$ MA. Accessed 11 October 2010).

13. Davies N, Duff M. Breast cancer screening for older women with intellectual disability living in group homes. J Intellect Disabil Res 2001;45(Pt 3):253-7.

14. Sullivan SG, Glasson EJ, Hussain R, et al. Breast cancer and the uptake of mammography screening services by women with intellectual disabilities. Prev Med 2003;37(5):507-12.

15. Wisdom JP, McGee MG, Horner-Johnson W, Michael YL, Adams E, Berlin M. Health disparities between women with and without disabilities: a review of the research. Soc Work Pub Health 2010;25(3):368-86.

16. Luckasson R, Coulter DL, Polloway EA, et al. Mental Retardation: Definition, Classification and Systems of Support. Washington, DC: American Association of Mental Retardation; 2002.

17. McLeroy K, Bibeau D, Stecker A, Glanz K. An ecological perspective on health promotion programs. Health Educ Q 1988;15(35):351-77.

18. Wilkinson JE, Bowen DJ, Freund K, Rosen AK. Evaluating cancer screening outcomes in a Department of Mental Retardation Database. Presented at: North American Primary Care Research Group, Montreal, Canada, November 2009.

19. US Preventive Services Task Force. Screening for breast cancer. 2009. Available at: http://www. uspreventiveservicestaskforce.org/uspstf/uspsbrca.htm. Accessed 16 September 2010.

20. Yang O, Rasmussen SA, Friedman JM. Mortality assoc with Down's syndrome in the USA from 1983 to 1997: a population-based study. Lancet 2002; 359(9311):1019-25.

21. Satge D. Breast cancer screening guidelines should be adapted in Down syndrome. Br Med J 2002; 324(7346):1155.

22. MMWR Quick Guide. Recommended adult immunization schedule-United States, 2010. Available at: http://www.cdc.gov/mmwr/PDF/wk/mm5901Immunization.pdf. Accessed 16 September 2010.

23. Shtatland S, Kleinman K, Cain EM. A new strategy of model building in Proc Logistic with automatic variable selection, validation, shrinkage and model averaging. SAS Users Group International (SUGI) 29 Proceedings. Montréal, Canada, May 9-12, 2004.

24. Balogh R, Oullette-Kuntz H, Bourne L, Lunsky Y, Colantonio A. Organising health care services for persons with an intellectual disability. Cochrane Database Systems Rev 2008;(4):CD007492.

25. McIlfatrick S, Taggart L, Truesdale-Kennedy M. Supporting women with intellectual disabilities to access breast cancer screening: a healthcare professional perspective. Eur J Cancer Care (Engl) 2011;20:412-20.

26. Kirby S, Hegarty J. Breast awareness within an intellectual disability setting. Eur J Oncol Nurs 2010; 14(4):328-36.

27. Tyler CV, Zyzanski SJ, Panaite V, Council L. Nursing perspectives on cancer screening in adults with intellectual and other developmental disabilities. Intellect Dev Disabil 2010;48(4):271-7.

28. Pham HH, Schrag D, Hargraves JL, Bach PB. Delivery of preventive services to older adults by primary care physicians. JAMA 2005;294(4):473-81.

29. Ferrante JM, Balasubramanian BA, Hudson SV, Crabtree BF. Principles of the patient-centered medical home and preventive services delivery. Ann Fam Med 2010;8(2):108-16.

30. Henderson CM, Rosasco M, Robinson LM, et al. Functional impairment severity is associated with 
health status among older persons with intellectual disability and cerebral palsy. J Intellect Disabil Res 2009;53(11):887-97.

31. Bershadsky J, Kane RL. Place of residence affects routine dental care in the intellectually and developmentally disabled adult population on Medicaid. Health Serv Res 2010;45(5 Pt 1):1376-89.

32. Feig SA, Hendrick RE. Radiation risk form screening mammography of women aged 40-49 years. J Natl Cancer Inst Monogr 1997;(22):119-124.

33. Moran R, Drane W, McDermott S, Dasari S, Scurry JB, Platt T. Obesity among people with and without mental retardation across adulthood. Obes Res 2005; 13(2):342-9.
34. Yamaki K. Body weight among adults with intellectual disability in the community. Ment Retard 2005; 43(1):1-10.

35. Rimmer JH, Braddock D, Fujiura G. Prevalence of obesity in adults with mental retardation: implications for health promotion and disease prevention. Ment Retard 1993;31(2):105-10.

36. Ferrante JM, Chen PH, Jacobs A. Breast and cervical cancer screening in obese minority women. J Womens Health (Larchmt) 2006;15(5):531-41.

37. Wilkinson JE, Deis C, Bowen DJ, Bokhour BG. "It's easier said than done": perspectives on mammography from women with intellectual disabilities. Ann Fam Med 2011;9(2):142-7. 